\title{
High-resolution three-dimensional ANGIE T1 mapping of the whole heart
}

\author{
Bhairav B Mehta ${ }^{1 *}$, Michael Salerno ${ }^{2,1}$, Frederick H Epstein ${ }^{1,3}$ \\ From 18th Annual SCMR Scientific Sessions \\ Nice, France. 4-7 February 2015
}

\begin{abstract}
Background
Assessment of fibrosis in thinner myocardial structures such as the right ventricular (RV) and left atrial walls would be valuable in disorders such as pulmonary hypertension, congenital heart disease, and atrial fibrillation. We recently developed a novel technique, termed ANGIE, which provides high-resolution 2D T1 mapping for assessment of thin structures such as the wall of the RV. However, high resolution 2D imaging is limited by lower SNR and time efficiency. A 3D image acquisition provides higher SNR and complete coverage of the heart. However standard 3D navigated techniques have prohibitively long scan times. Thus, the aim of the present study was to extend ANGIE to perform high-resolution three-dimensional (3D) T1 mapping of the whole heart within a clinically acceptable scan time.
\end{abstract}

\section{Methods}

A novel image reconstruction algorithm, which uses compressed sensing (CS) with local low-rank sparsity in conjunction with partial Fourier and parallel imaging, was developed to achieve high acceleration $(R=10)$ for $3 D$ ANGIE. High-resolution $\left(1.4 \times 1.4 \times 4 \mathrm{~mm}^{3}\right)$ T1 mapping of the whole heart was performed using 3D ANGIE in three healthy volunteers on a $1.5 \mathrm{~T}$ system (Avanto Siemens). Imaging parameters included: matrix size $=224 \times 224 \times 26$, number of inversion times $=12$, and partial Fourier reduction factor of $3 / 4$ along phase and partition encode. Additionally, 2D MOLLI $\left(2.5 \times 2 \times 4 \mathrm{~mm}^{3}\right)$ and $2 \mathrm{D}$ ANGIE $\left(1.3 \times 1.3 \times 4 \mathrm{~mm}^{3}\right)$ scans were performed at three different short-axis slice positions.

\section{Results}

Figure 1 illustrates example reconstructed (A-D), fully sampled $(\mathrm{E}-\mathrm{H})$ and reconstruction error $(\mathrm{I}-\mathrm{L})$ images

${ }^{1}$ Department of Biomedical Engineering, University of Virginia, Charlottesville, VA, USA

Full list of author information is available at the end of the article from a retrospectively accelerated $(R=10) 3 D$ ANGIE dataset. The image reconstruction algorithm effectively suppresses aliasing artifacts and retains spatial resolution, illustrating the capability of achieving a high acceleration rate $(R=10)$ using the proposed reconstruction algorithm. Figure 2 illustrates example T1 maps from a healthy volunteer acquired using all three techniques with prospective acceleration at three different slice positions across the ventricle. 2D MOLLI (Fig. 2G-I) provides high SNR but incomplete definition of the RV wall, whereas 2D ANGIE (Fig. 2D-F) provides good definition of the RV wall but lower SNR. However, 3D ANGIE (Fig. 2A-C) provides both good definition of the RV wall as well as high SNR. The left ventricular myocardium and blood T1 estimates of 3D ANGIE (LV: $1013 \pm 67 \mathrm{~ms}$, blood: $1501 \pm 44 \mathrm{~ms})$ were in close agreement with 2D MOLLI (LV: $994 \pm 81 \mathrm{~ms}$, blood: $1507 \pm 68 \mathrm{~ms}$ ). The RV T1 estimates of 3D ANGIE $(1022 \pm 85 \mathrm{~ms})$ were in close agreement with 2D ANGIE $(1028 \pm 89 \mathrm{~ms})$. The acquisition time and navigator acceptance for $3 \mathrm{D}$ ANGIE was $6.6 \pm 2.7 \mathrm{mins}$ and $67 \pm 19 \%$, while for $2 \mathrm{D}$ ANGIE was $2.2 \pm 1.2 \mathrm{mins}$ (per slice) and $60 \pm 16 \%$.

\section{Conclusions}

3D ANGIE provides accurate high-resolution $\left(1.4 \times 1.4 \times 4 \mathrm{~mm}^{3}\right)$ native $\mathrm{T} 1 \mathrm{maps}$ of the whole heart within a clinically acceptable scan time.

\section{Funding}

NIH R01 EB 001763, AHA Grant-in-Aid 12GRNT12050301, AHA 14PRE20210008, and Siemens Medical Solutions.

\section{Authors' details}

'Department of Biomedical Engineering, University of Virginia, Charlottesville, VA, USA. ²Medicine (Cardiology), University of Virginia, Charlottesville, VA, USA. ${ }^{3}$ Department of Radiology and Medical Imaging, University of Virginia, Charlottesville, VA, USA. 

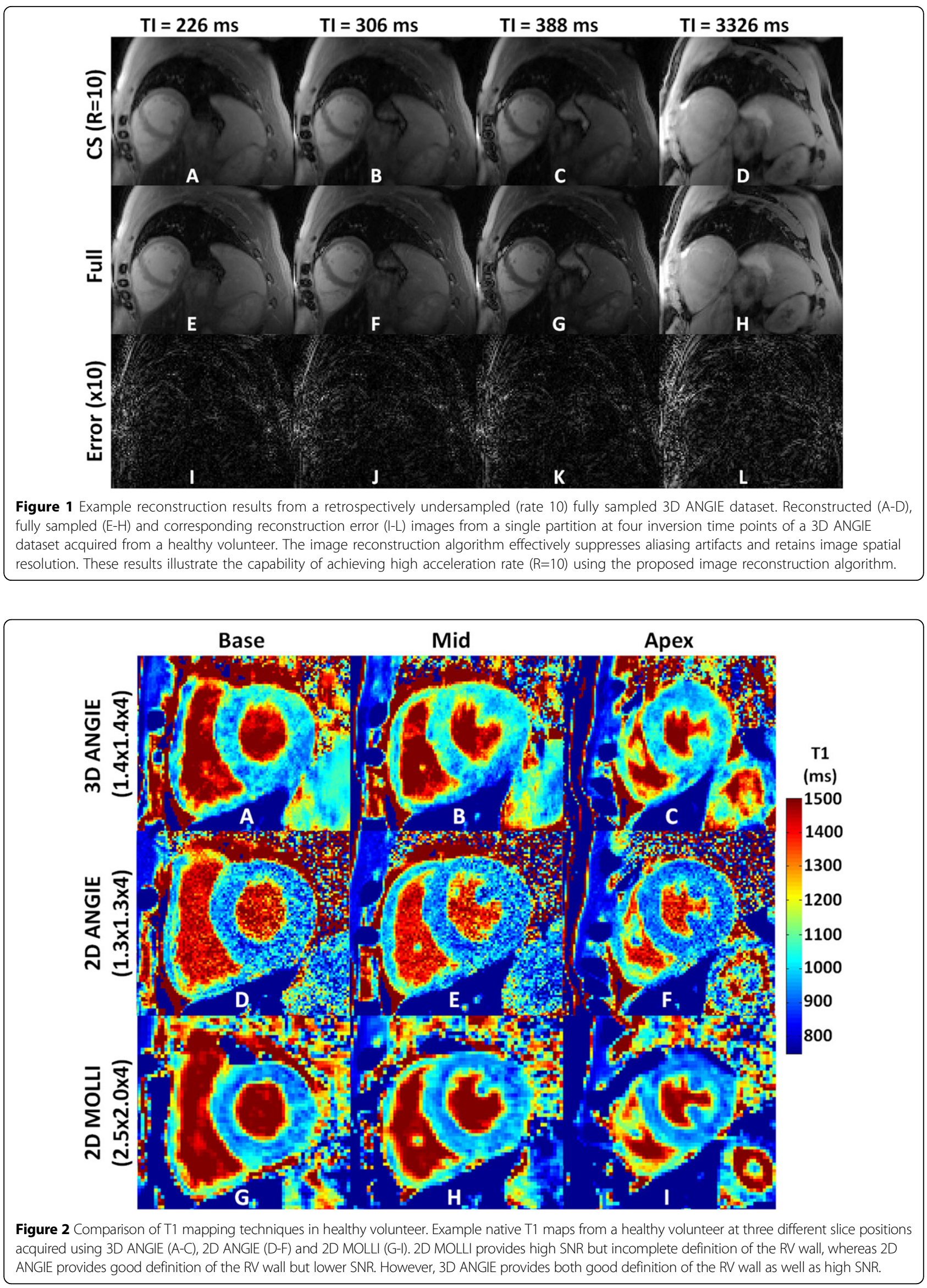

and take full advantage of:

- Convenient online submission

- Thorough peer review

- No space constraints or color figure charges

- Immediate publication on acceptance

- Inclusion in PubMed, CAS, Scopus and Google Scholar

- Research which is freely available for redistribution 